\title{
Comparison of the Efficacy of Three Natural Surfactants in Preterm Turkish Newborns with Respiratory Distress Syndrome
}

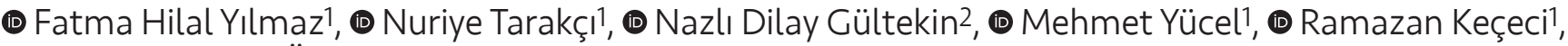 \\ (1) Elif Nur Yıldırım Öztürk33, (1) Hüseyin Altunhan
}

${ }^{1}$ Necmettin Erbakan University Meram Medical Faculty, Department of Neonatology, Konya, Turkey

2Van Training and Research Hospital, Clinic of Neonatology, Van, Turkey

${ }^{3}$ Necmettin Erbakan University Meram Faculty of Medicine Hospital, Clinic of Public Health, Konya, Turkey

\begin{abstract}
Aim: To determine the efficacy of three natural surfactant preparations in our community and the short- and long-term results of these on preterm infants.

Materials and Methods: This was a retrospective research on 193 premature babies with respiratory distress syndrome (RDS). The patients were divided into three groups, each of which received one of three surfactants: Group 1; beractant (100 mg $/ \mathrm{kg}$ ); group 2; poractant alfa (first dose of $200 \mathrm{mg} / \mathrm{kg}$, recurrent doses of $100 \mathrm{mg} / \mathrm{kg}$ ); group 3; calfactant $(100 \mathrm{mg} / \mathrm{kg}$ ). The groups were compared according to demographic characteristics, 1- and 5-minute Apgar scores, weight percentiles by gestational week, presence of pulmonary hemorrhage, surfactant dose repetition, air leak, bronchopulmonary dysplasia (BPD), stage of intraventricular hemorrhage (IVH), necrotizing enterocolitis (NEC), hemodynamically significantpatent ductus arteriosus (hs-PDA) and its medical or surgical treatment, retinopathy of premature (ROP) and its treatment, sepsis, ventilation time (both non-invasive and invasive), free oxygen need time, time to start full enteral feeding, discharge time, and mortality.

Results: A total of 193 preterm infants with a mean gestational age of $28.9 \pm 3.1$ weeks and mean birth weight of 1,190.4 \pm 504.3 grams were included in this study. The neonates were allocated into three different groups randomly, namely group- $1(n=77)$, group-2 ( $n=59)$, and group-3 $(n=57)$. There were no differences in the clinical and demographic features of the groups. The incidence of pulmonary hemorrhage, surfactant dose repetition, air leak, ventilation time for both non-invasive and invasive, free oxygen need time, hs-PDA and surgical treatment of PDA, BPD, NEC ( $\geq$ stage II), IVH (>stage III), ROP, time to start full enteral feeding, and discharge time were similar between the study groups. The sepsis and mortality rates were lower in group 3 compared to groups 1 and $2(p=0.015, p=0.001)$.
\end{abstract}

Conclusion: In this study, beractant, proctant alfa and calfactant had clinically similar efficacy in patients with RDS.

Keywords: Respiratory distress, neonate, surfactant, Turkey

\section{Introduction}

Respiratory distress syndrome (RDS) continues to be one of the main causes of morbidity and mortality in preterm newborns admitted to neonatal intensive care units (NICU). Atelectasis and progressive respiratory failure develop due to a lack of surfactant in RDS (1). Preterm infants with RDS have inadequate surfactant pools, as well as immature surfactant composition and function. Surfactant is a substance produced by type II pneumocytes which form a lipid bi-layer over the inner surface of the 
alveoli. This lipid bilayer reduces the interaction between molecules at the alveolar air-liquid interface, lowering alveolar surface tension and stabilizing alveoli and the end of expiration (2). Surfactant deficiency and dysfunction leads to increased alveolar surface tension, which results in alveolar acinar collapse and decreased lung aeration. Surfactant replacement therapy forms the cornerstone of the management of moderate to severe RDS among preterm neonates and it is associated with reduced mortality and pulmonary air leak $(3,4)$. Clinically, RDS occurs in the early postnatal period with signs of tachypnea, retraction, groaning and respiratory distress accompanied by cyanosis. Respiratory insufficiency can be detected by blood gas values and its diagnosis is supported by classical ground glass and air bronchograms on chest X-ray. Transient tachypnea of the newborn, pneumonia, air leak syndromes, cyanotic congenital heart diseases and other extrapulmonary systemic diseases should be considered in the differential diagnosis (5).

Currently, there are three animal-derived lung surfactant replacement products - calfactant (InfasurfR), beractant (Survanta ${ }^{R}$ ), and poractant alfa (Curosurf ${ }^{R}$ )- in Turkey that are Food and Drug Administration approved for the treatment of newborn infants with RDS. Until May 2017 in our country, poractant alfa and beractant were the only available animalderived natural surfactants. Therefore, there are not enough objective studies comparing the efficacy of these three preparations. The aim of this study was to determine the efficacy of these three natural surfactant preparations in our community and to determine the short- and long-term outcomes of these on preterm infants.

\section{Materials and Methods}

\section{Design}

This research was performed as a retrospective study between May 2017 and September 2019 in the tertiary NICU of Necmettin Erbakan University Meram Medical Faculty.

Ethics Committee approval for this study was obtained from Necmettin Erbakan University with the Ethics Committee decision number of 2019/2105.

\section{Patients}

During the study period, 223 patients were diagnosed with RDS in the NICU between $22^{\text {th }}$ and $34^{\text {th }}$ weeks of gestation. Exclusion criteria included congenital lung diseases, chromosomal abnormalities or major congenital malformations, congenital cyanotic cardiac disease and meconium aspiration syndrome. One hundred and ninety- three of the patients met the study criteria (Figure 1). Patients were evaluated clinically and by chest radiography for RDS diagnostic criteria. RDS was diagnosed clinically with early respiratory distress manifesting by symptoms of groaning, cyanosis, retractions and tachypnea. The diagnosis was confirmed by a blood gas analysis and chest X-ray with the classical "ground glass" appearance and air bronchograms. Surfactant therapy was administered prophylactically or as a rescue therapy, depending on the clinical presentation, in accordance with the European Consensus Guidelines (5) and the prospectus for each drug. The surfactant selection for each patient was determined by drawing lots. In the delivery room, babies were treated according to European guidelines (5). Nasal continuous positive airway pressure (CPAP) was started in the delivery room immediately after stabilization or while being admitted to the NICU. In the NICU, appropriately sized nasal canulas or masks (Fisher \& Paykel Healthcare, Auckland) and Leoni Plus ventilator (HeinenpL $€$ owenstein, Bad Ems, Germany) were placed in the nasal CPAP mode. When required, mechanical ventilation was set to be $\mathrm{PaO}_{2}>50 \mathrm{mmHg}, \mathrm{PaCO}_{2} 55-65 \mathrm{mmHg}$ and $\mathrm{SpO}_{2}$ 90-95\%. Surfactants were given by the InSURE (intubationsurfactant-extubation) method when the inhaled oxygen fraction $\left(\mathrm{FiO}_{2}\right)$ was higher than 0.4. Babies who were administered surfactant were then switched to nasal CPAP mode as soon as possible, depending on their respiratory conditions. Repeated surfactant doses were administered if babies had MAP>7 and $\mathrm{FiO}_{2}>0.3$. When intubated in the delivery room or NICU, the surfactant was given through an endotracheal tube. Surfactants were injected into the

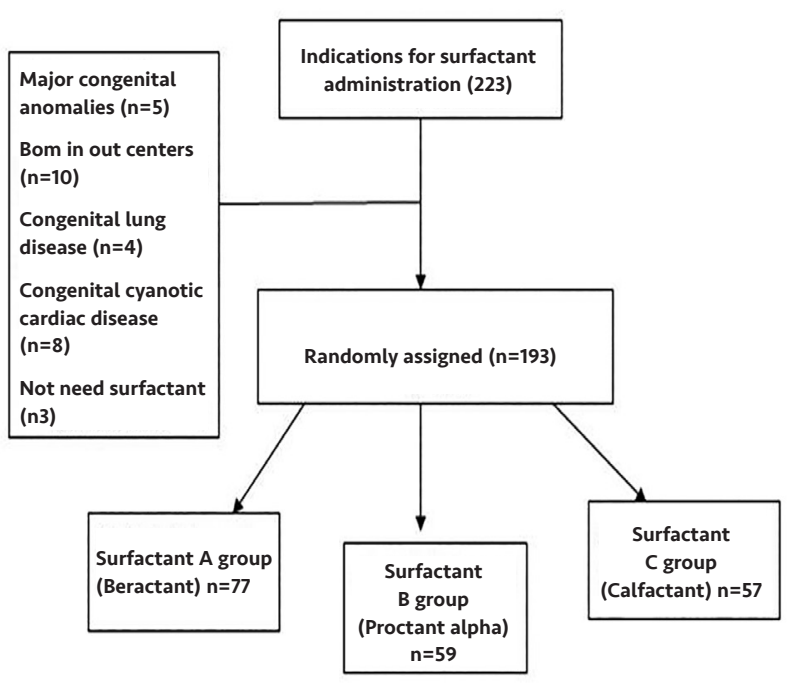

Figure 1. Flow chart of the study group 
trachea via an orogastric tube through an endotracheal tube.

The patients were divided into three groups; Group 1; beractant (Survanta, AbbVie Inc, North Chicago, IL, USA; $100 \mathrm{mg} / \mathrm{kg}, 4 \mathrm{~mL} / \mathrm{kg}$ ); group 2; poractant alfa (CurosurfVR, Chiesi, Parma, Italy; first dose of $200 \mathrm{mg} / \mathrm{kg}, 2.5 \mathrm{~mL} /$ $\mathrm{kg}$, recurrent doses of $100 \mathrm{mg} / \mathrm{kg}, 1.25 \mathrm{~mL} / \mathrm{kg}$ ); group 3; calfactant (Infasurf, ONY Biotech, NY, USA; $100 \mathrm{mg} / \mathrm{kg}$, $3 \mathrm{~mL} / \mathrm{kg}$ ).

The groups were compared according to demographic characteristics, 1- and 5-minute Apgar scores, weight percentiles according to gestational week, pulmonary hemorrhage, surfactant dose repetition, air leak, BPD, stage of IVH, NEC, hs-PDA and its medical or surgical treatment, ROP and its treatment, sepsis, ventilation time (both noninvasive and invasive), free oxygen need time, time to start full enteral feeding, discharge time, and mortality.

Hemodynamically-significant PDA (hs-PDA) was defined with echocardiographic evidence of ductal lumen over $1.5 \mathrm{~mm}$ and left atrium diameter/aortic root diameter ratio of over 1.4 and documentation of left to right shunt. Bronchopulmonary dysplasia was defined as the need for oxygen at 36 weeks postmenstrual age or at the time of discharge or transfer to Level 2 NICUs (6); NEC $\geq$ Stage 2 (7); and severe brain injury, which included IVH $\geq$ Stage 3.

The examined maternal variables included the type of delivery, maternal age, antenatal steroid treatment, maternal gestational diabetes, maternal preeclampsia and clinical chorioamnionitis (defined as the presence of fever with one or more of the following: maternal leukocytosis
$>15,000 / \mathrm{mm}^{3}$, fetal tachycardia, uterine tenderness or foulsmelling amniotic fluid).

\section{Statistical Analysis}

The data related to the research were transferred to computer and the analyses were performed with SPSS. The mean \pm standard deviation and median (minimummaksimum) were summarized in the summary of the numerical data; Numbers and percentages were used to summarize the categorical data. One-Way analysis of variance (ANOVA) and Welch's ANOVA were used for numerical data to investigate the relationships between the groups; chi-square test was used for categorical data. After the analysis of variance, Tukey HSD was used as a post-hoc test when deemed necessary. $\mathrm{P}<0.05$ was accepted for statistical significance.

\section{Results}

A total of 193 preterm infants with a mean gestational age of $28.9 \pm 3.1$ weeks and mean birth weight of $1,190.4 \pm 504.3$ grams were enrolled and allocated into three groups. Beractant (group 1) was administrated to 77 (39.8\%) neonates, poractant alfa (group 2) to 59 (30.5\%), and calfactant (group 3) to 57 (29.5\%). The gestational age of group 1 was $29.16 \pm 2.9$ weeks, group 2 was $28.4 \pm 3.5$ weeks and group 3 was $29.0 \pm 2.8$; and the birth weight of group 1 was $1,236.38 \pm 563.6 \mathrm{~g}$, group 2 was $1,222.4 \pm 519.4 \mathrm{~g}$ and group 3 was $1,198.7 \pm 391.9 \mathrm{~g}$. There were no differences between the groups with regard to gestational age, birth weight, maternal age, 1- and 5-minute Apgar scores, antenatal corticosteroids, antenatal antibiotics, maternal gestational

Table I. Demographic and clinical characteristics of the subjects by groups

\begin{tabular}{|c|c|c|c|c|}
\hline Characteristics & $\begin{array}{l}\text { Group } 1 \\
\text { (Beractant) } \\
(\mathrm{n}=77)\end{array}$ & $\begin{array}{l}\text { Group } 2 \\
\text { (Poractant alfa) } \\
(n=59)\end{array}$ & $\begin{array}{l}\text { Group } 3 \\
\text { (Calfactant) } \\
(n=57)\end{array}$ & p-value \\
\hline Birth weight $(g)$, mean \pm SD & $1,236.38 \pm 563.6$ & $1,222.4 \pm 519.4$ & $1,198.7 \pm 391.9$ & 0.42 \\
\hline Gestational age $(w)$, mean \pm SD & $29.16 \pm 2.9$ & $28.4 \pm 3.5$ & $29.0 \pm 2.8$ & 0.32 \\
\hline Maternal age, mean (SD) & $28.97 \pm 5.7$ & $28.9 \pm 6.5$ & $29.1 \pm 6.2$ & 0.9 \\
\hline 5-min Apgar, mean (SD) & $5.56 \pm 1.46$ & $5.78 \pm 1.69$ & $5.37 \pm 1.44$ & 0.35 \\
\hline 1-min Apgar, mean (SD) & $4.45 \pm 1.6$ & $4.27 \pm 1.82$ & $4.21 \pm 1.69$ & 0.68 \\
\hline Maternal gestational diabetes $\mathrm{n}(\%)$ & $3(3.9)$ & $5(8.5)$ & $6(10.5)$ & 0.31 \\
\hline Maternal preeclampsia, n (\%) & $17(22.1)$ & $19(32.2)$ & $11(19.3)$ & 0.22 \\
\hline Antenatal antibiotics & $13(16.9)$ & $8(13.6)$ & $11(19.3)$ & 0.7 \\
\hline Chorioamnionitis, n (\%) & $4(5.2)$ & $9(15.3)$ & $10(17.5)$ & 0.59 \\
\hline Antenatal steroid use, n (\%) & $41(53.2)$ & $34(57.6)$ & $33(57.9)$ & 0.82 \\
\hline SGA, n (\%) & $18(23.4)$ & $8(13.6)$ & $8(14)$ & 0.23 \\
\hline
\end{tabular}


diabetes mellitus, maternal preeclampsia, chorioamnionitis or SGA (Table I).

Table II shows a comparison of the groups in terms of RDS-related results respiratory outcomes. Pulmonary hemorrhage was lower in group 3, but there was no statistically significant difference $(p=0.07)$. Although the number of cases with air leakage was higher in group 2 , there was no statistically significant difference $(p=0.13)$. There were no differences with regard to surfactant redosing, invasive mechanical ventilation, non-invasive mechanical ventilation and free oxygen need time.

The incidence of hs-PDA and surgical treatment of PDA, BPD, NEC ( $\geq$ stage 2), high grade IVH (>stage 3 ), ROP, and time to start full enteral feeding were similar between the study groups, as was discharge time. Sepsis and mortality were lower in group 3 compared to the groups 1 and 2 $(p=0.015, p=0.001$ respectively) (Table III). Treatment of ROP was higher in group 2 compared to the other groups but

\begin{tabular}{|c|c|c|c|c|}
\hline Characteristics & $\begin{array}{l}\text { Group } 1 \\
\text { (Beractant) }(n=77)\end{array}$ & $\begin{array}{l}\text { Group } 2 \\
\text { (Poractant alfa) } \\
(n=59)\end{array}$ & $\begin{array}{l}\text { Group } 3 \\
\text { (Calfactant) }(n=57)\end{array}$ & p-value \\
\hline Surfactant redosing, n (\%) & $28(36.4)$ & $17(28.8)$ & $15(26.3)$ & 0.41 \\
\hline Pulmonary hemorrhage, $\mathrm{n}(\%)$ & $14(18.4)$ & $10(17.2)$ & $3(5.3)$ & 0.07 \\
\hline Pulmonary air leak, n (\%) & $2(2.6)$ & $5(8.5)$ & $1(1.8)$ & 0.13 \\
\hline $\begin{array}{l}\text { Invasive mechanical ventilation time (days), } \\
\text { mean (SD) }\end{array}$ & $8.4 \pm 13.2$ & $8 \pm 11.7$ & $9 \pm 10.7$ & 0.9 \\
\hline $\begin{array}{l}\text { Non-invasive mechanical ventilation time } \\
\text { (days), mean (SD) }\end{array}$ & $12.0 \pm 15.4$ & $10.4 \pm 10.8$ & $15.2 \pm 16.7$ & 0.25 \\
\hline $\begin{array}{l}\text { Duration of free oxygen need (days), mean } \\
\text { (SD) }\end{array}$ & $18.3 \pm 18.03$ & $16.7 \pm 14.3$ & $15.2 \pm 17.4$ & 0.15 \\
\hline
\end{tabular}

\begin{tabular}{|c|c|c|c|c|}
\hline Characteristics & $\begin{array}{l}\text { Group } 1 \text { (Beractant) } \\
(\mathrm{n}=77)\end{array}$ & $\begin{array}{l}\text { Group } 2 \text { (Poractant alfa) } \\
(n=59)\end{array}$ & $\begin{array}{l}\text { Group } 3 \text { (Calfactant) } \\
(n=57)\end{array}$ & p-value \\
\hline hs-PDA, n (\%) & $\begin{array}{l}\text { Positive } 19(25.3) \\
\text { Negative } 56(74.7)\end{array}$ & $\begin{array}{l}\text { Positive } 15(27.3) \\
\text { Negative } 40(72.7)\end{array}$ & $\begin{array}{l}\text { Positive } 10 \text { (18.2) } \\
\text { Negative } 45 \text { (81.8) }\end{array}$ & 0.49 \\
\hline Surgical treatment of PDA, $n(\%)$ & $\begin{array}{l}\text { Positive } 3(15.8) \\
\text { Negative } 16(84.2)\end{array}$ & $\begin{array}{l}\text { Positive } 1 \text { (6.7) } \\
\text { Negative } 14 \text { (93.3) }\end{array}$ & $\begin{array}{l}\text { Positive } 2(20) \\
\text { Negative } 8(80)\end{array}$ & 0.6 \\
\hline $\mathrm{BPD}, \mathrm{n}(\%)$ & $\begin{array}{l}\text { Positive } 16(27.1) \\
\text { Negative } 43(72.9)\end{array}$ & $\begin{array}{l}\text { Positive } 7 \text { (18.4) } \\
\text { Negative } 31 \text { (81.6) }\end{array}$ & $\begin{array}{l}\text { Positive } 15(30) \\
\text { Negative } 35(70)\end{array}$ & 0.45 \\
\hline NEC, n (\%) & $\begin{array}{l}\text { Positive } 8 \text { (11.3) } \\
\text { Negative } 63(88.7)\end{array}$ & $\begin{array}{l}\text { Positive } 7 \text { (14) } \\
\text { Negative } 43(86)\end{array}$ & $\begin{array}{l}\text { Positive } 3(5.7) \\
\text { Negative } 50(94.3)\end{array}$ & 0.36 \\
\hline $\mathrm{IVH}, \mathrm{n}(\%)$ & $\begin{array}{l}\text { Positive } 21(28.4) \\
\text { Negative } 53(71.6)\end{array}$ & $\begin{array}{l}\text { Positive } 14(24.5) \\
\text { Negative } 41 \text { (75.5) }\end{array}$ & $\begin{array}{l}\text { Positive } 13(22.8) \\
\text { Negative } 44(77.2)\end{array}$ & 0.82 \\
\hline ROP, n (\%) & $\begin{array}{l}\text { Positive } 22(36.7) \\
\text { Negative } 38(63.3)\end{array}$ & $\begin{array}{l}\text { Positive } 12(30.8) \\
\text { Negative } 27(69.2)\end{array}$ & $\begin{array}{l}\text { Positive } 15(29.4) \\
\text { Negative } 36(70.6)\end{array}$ & 0.68 \\
\hline Treatment of ROP, n (\%) & $\begin{array}{l}\text { Positive } 7 \text { (29.2) } \\
\text { Negative } 17 \text { (70.8) }\end{array}$ & $\begin{array}{l}\text { Positive } 6(85.7) \\
\text { Negative } 1(14.3)\end{array}$ & $\begin{array}{l}\text { Positive } 4(40) \\
\text { Negative } 6(60)\end{array}$ & $\ldots$ \\
\hline $\begin{array}{l}\text { Time to enter full enteral feeding, } \\
\text { (days), mean (SD) }\end{array}$ & $18 \pm 11.8$ & $14.2 \pm 7.1$ & $17.2 \pm 11$ & 0.19 \\
\hline Discharge time, (day), mean (SD) & $52 \pm 35.2$ & $49.3 \pm 28.5$ & $52.5 \pm 32.4$ & 0.9 \\
\hline Sepsis, n (\%) & $\begin{array}{l}\text { Positive } 23 \text { (31) } \\
\text { Negative } 51 \text { (68.9) }\end{array}$ & $\begin{array}{l}\text { Positive } 21 \text { (38.2) } \\
\text { Negative } 34 \text { (61.8) }\end{array}$ & $\begin{array}{l}\text { Positive } 8(14.3) \\
\text { Negative } 48(85.7)\end{array}$ & 0.015 \\
\hline Mortality, n (\%) & $\begin{array}{l}\text { Positive } 16(20.8) \\
\text { Negative } 61(79.2)\end{array}$ & $\begin{array}{l}\text { Positive } 18(30.5) \\
\text { Negative } 41(69.5)\end{array}$ & $\begin{array}{l}\text { Positive } 8 \text { (14) } \\
\text { Negative } 49 \text { ( } 86)\end{array}$ & 0.001 \\
\hline
\end{tabular}


statistical significance could not be shown, as the number of patients in the groups was insufficient.

\section{Discussion}

In this study, we compared the clinical efficacy of calfactant, which has recently become available in our country, beractant and poractant alfa among preterm infants with RDS. In patients with respiratory distress, the surfactant, a phospholipid mixture, reduces surface tension to keep the alveoli open. The efficacy of surfactant treatment for the treatment of RDS has been fully specified; however, it is not clear which type of natural surfactant should be employed. There are studies in the literature comparing these three natural surfactants. However, there are not enough studies in Turkey making this comparison.

We found that calfactant, beractant and poractant alfa had similar relative effectiveness on pulmonary hemorrhage, surfactant redosing, prevention of air leak syndromes, duration of invasive mechanical ventilation, duration of non-invasive mechanical ventilation and length of free oxygen need, hs-PDA, surgical treatment of PDA, NEC, IVH, $B P D, R O P$, treatment of ROP, time to start full enteral feeding and discharge time. Only sepsis and mortality were lower in group 3 than the others. In a multi-center study by Trembath et al. (8), in which they compared beractant, calfactant and poractant, there were no differences in outcomes obtained including air leak syndromes, NEC, IVH (grade 3 or 4), BPD and mortality. The authors concluded that the differences between the surfactants included in previous studies with regard to mortality and outcomes did not show the actual differences in effectiveness of surfactants and that it was related to variations in outcomes attributed to different institutions. In this retrospective study, the median gestational age, below the 37 weeks of gestation, was 30 weeks and the infants had a median birth weight of 1,435 grams. In contrast, our study had a lower mean birth weight and gestational week; we thus think we produced similar but more objective data. It is known that, with surfactant administration, the incidence of air leak reduces in patients with RDS. This, in turn, means a reduction in associated morbidities including hypoxia, hypotension and IVH (9). Although it was determined in our study that the incidence of patients with air leak was higher in the poractant alfa group compared to the other two groups, this was not statistically significant. In a retrospective study, Jeon et al. (10) compared three natural surfactants in patients with a mean gestational age of $28^{\text {th }}$ weeks and a birth weight of 1,130g. They found that all three surfactants were similarly effective in respiratory outcomes and secondary outcomes including complications of prematurity. Although they had largely similar results to our study, they could not randomize the patients because the study was retrospective and they left results of patients under 24 weeks of gestation unrecorded. In contrast to several studies on this issue in the literature, our study also included infants born at $24-22^{\text {th }}$ weeks' gestation.

In the study of Karadag et al. (11), surfactant redosing was more frequent in the beractant group. However, the poractant alfa group had a higher perfusion index and better oxygenation index after surfactant. In the study by Dilli et al. (12), however, surfactant redosing was determined to be more frequent in the calfactant group. However, in neonates with RDS, poractant alfa and beractant lessened oxygen demand to a similar extent in accordance with lung ultrasonography findings. They seem to be superior to calfactant. In contrast to what Dilli et al. (12) expressed, in our study, there were no differences between the groups with regard to redosing. In addition, the patients' duration of ventilation support, which is an indicator of oxygenation, was similar in all three groups.

Similar studies have discussed the comparative efficacy of surfactants on mortality $(13,14)$. Ramanathan (15) reported that poractant alfa was associated with decreased mortality rates compared to beractant or calfactant and it was suggested that the differences in mortality rates might be related to the composition of these surfactants, including higher amounts of phospholipids and plasmalogens and a smaller volume of poractant alfa compared to other animal-derived surfactants. Ramanathan et al. (16), conducted a retrospective observational cohort study in the US, which compared poractant alfa with calfactant and beractant. They also concluded that poractant alfa at a dose of $200 \mathrm{mg} / \mathrm{kg}$ was associated with reduced mortality rates compared with calfactant at a dose of 105 $\mathrm{mg} / \mathrm{kg}$ or beractant at a dose of $100 \mathrm{mg} / \mathrm{kg}$. The same dose of poractant alfa and beractant at a dose of 100 $\mathrm{mg} / \mathrm{kg}$ resulted in no difference in mortality rates, and mortality rates were also similar to those of calfactant and beractant. In our study, causes of death in groups I and II included particularly sepsis, as well as causes including pneumothorax and hypoxic respiratory failure. Mortality and sepsis rates were determined to be significantly lower in group III compared to the other two groups. We therefore directly correlate mortality with sepsis, not with RDS. The low mortality rate in the calfactant group was attributed to the low sepsis rate. Low sepsis in this group is a completely random result. We know that there is no statistically significant risk factor (e.g., birth week, birth weight, RDS- 
related respiratory outcomes) that increase mortality other than sepsis among the groups. Furthermore, we could not directly correlate the effectiveness of surfactant molecules with mortality and sepsis rates, as we are of the opinion that mortality and sepsis are related to several factors other than the severity of RDS.

The need for cost-effectiveness studies has increased with the increased number of alternatives in the surfactant market. Sekar et al. (17), compared length of stay, costs, mechanical ventilation, and mortality in preterm infants with beractant, calfactant, and poractant alfa for RDS. They found adjusted NICU length of stay and costs were similar among the three groups. Infants receiving poractant alfa were less likely to be on mechanical ventilation at days 3 and 7, and poractant alfa treatment was associated with lower odds of NICU mortality when compared to calfactant. In this study, there was no association between the duration of respiratory support and mortality results. Additionally, we did not investigate cost-effectiveness in this study. Nonetheless, we examined the clinical efficacy of three natural surfactants used in our ethnicity and our own medical practice. Hence, this study, as an important tool for comparative effectiveness research, helps clinicians and buyers reach a decision on product preference (18).

\section{Conclusion}

In this study, beractant, poractant alfa, and calfactant had clinically similar efficacy in patients with RDS. Therefore, the decision regarding which surfactant preparation to use should be based on factors other than effectiveness.

\section{Acknowledgments}

We thank the NICU nurses involved in the care of the neonates studied in this report.

\section{Ethics}

Ethics Committee Approval: Ethics Committee approval for this study was obtained from Necmettin Erbakan University with the Ethics Committee decision number of 2019/2105.

Informed Consent: Retrospective study.

Peer-review: Externally peer-reviewed.

\section{Authorship Contributions}

Concept: F.H.Y., Design: F.H.Y., Data Collection or Processing: N.D.G., M.Y., Analysis or Interpretation: R.K., E.N.Y.Ö., Literature Search: N.T., Writing: H.A.

Conflict of Interest: No conflict of interest was declared by the authors.
Financial Disclosure: The authors declared that this study received no financial support.

\section{References}

1. Edwards MO, Kotecha SJ, Kotecha S. Respiratory distress of the term newborn infant. Paediatr Respir Rev 2013; 14:29-36.

2. Agrons GA, Courtney SE, Stocker JT, Markowitz RI. Lung disease in premature neonates: radiologic-pathologic correlation. Radiographics 2005; 25:1047-73.

3. Pfister RH, Soll R, Wiswell TE. Protein-containing synthetic surfactant versus protein-free synthetic surfactant for the prevention and treatment of respiratory distress syndrome. Cochrane Database Syst Rev 2009; 4:CD006180. doi: 10.1002/14651858.CD006180.pub2.

4. Seger N, Soll R. Animal derived surfactant extract for treatment of respiratory distress syndrome. Cochrane Database Syst Rev 2009; 2:CD007836. doi: 10.1002/14651858.CD007836.

5. Sweet DG, Carnielli V, Greisen G, et al. European Consensus Guidelines on the management of respiratory distress syndrome - 2016 update. Neonatology 2017; 111:107-25.

6. Zonnenberg I, de Waal K. The definition of a haemodynamic significant duct in randomized controlled trials: A systematic literature review. Acta Paediatr 2012; 101:247-51.

7. Bell MJ, Ternberg IL, Feigin RD, Keating JP, Marshall R, Barton L. Neonatal necrotizing enterocolitis: therapeutic decisions based upon clinical staging. Ann Surg 1978; 187:1-7.

8. Trembath A, Hornik CP, Clark R, Smith PB, Daniels ), Laughon $M$. Comparative effectiveness of surfactant preparations in premature infants. J Pediatr 2013; 163:955-60.

9. Singh N, Hawley K, Viswanathan K. Efficacy of porcine versus bovine surfactants for preterm newborns with respiratory distress syndrome: a systematic review and metanalysis. Pediatrics 2011; 128:1588-95.

10. Jeon $\mathrm{CW}$, Oh M, Sin JB. Efficacy of surfactant-TA, Calfactant and poractant alfa for preterm infants with respiratory distress syndrome: a retrospective study. Yonsei Med I 2015; 56:433-9.

11. Karadag N, Dilli D, Zenciroglu A, et al. Perfusion index variability in preterm infants treated with two different natural surfactants for respiratory distress syndrome. Am J Perinatol 2014; 31:101522.

12. Dilli $\mathrm{D}$, Çakmakçı $\mathrm{E}$, Akduman $\mathrm{H}$, et al. Comparison of three natural surfactants according to lung ultrasonography scores in newborns with respiratory distress syndrome. I Matern Fetal Neonatal Med 2019: 24:1-7.

13. Egan EA. In response to mortality in preterm infants with respiratory distress syndrome treated with poractant alfa, calfactant, or beractant: a retrospective study. J Perinatol 2013; 33:165-6.

14. Cummings J). Is there evidence for a mortality difference between natural surfactants? J Perinatol 2013; 33:161-2

15. Ramanathan R. Animal-derived surfactants: where are we? The evidence from randomized, controlled clinical trials. J Perinatol 2009; 29(Suppl 2):S38-43. 
Yilmaz et al.

16. Ramanathan R, Bhatia J, Sekar K, Ernst FR. Mortality in preterm infants with respiratory distress syndrome treated with poractant alfa, calfactant or beractant: a retrospective study. J Perinatol 2013; 33:119-25.

17. Sekar K, Fuentes D, Krukas-Hampel MR, Ernst FR. Health economics and outcomes of surfactant treatments for respiratory distress syndrome among preterm infants in US level III/IV neonatal intensive care units. J Pediatr Pharmacol Ther 2019; 24:117-27.

18. Sturmer T, Jonsson Funk M, Poole C, Brookhart MA. Nonexperimental comparative effectiveness research using linked healthcare databases. Epidemiology 2011; 22:298-301. 